\title{
The effects of low dose leukotriene receptor antagonist therapy on airway remodeling and cysteinyl leukotriene expression in a mouse asthma model
}

\author{
M. Hamdi Muz ${ }^{1}$, Figen Deveci ${ }^{1,5}$, \\ Yasemin Bulut ${ }^{2}$, Nevin Ilhan ${ }^{3}$, \\ Hayrettin Yekeler $^{4}$ and Teyfik Turgut ${ }^{1}$ \\ ${ }^{1}$ Department of Chest Diseases \\ ${ }^{2}$ Department of Microbiology and Clinical Microbiology \\ ${ }^{3}$ Department of Biochemistry and Clinical Biochemistry \\ ${ }^{4}$ Department of Pathology \\ Elazi ğState Hospital, Elazig, Turkey \\ ${ }^{5}$ Corresponding author: Tel, 90-0-424-2333555/1586; \\ Fax, 90-0-424-2388096; E-mail, fgndeveci@yahoo.com
}

Accepted 15 February 2006

Abbreviations: EIA, enzyme immunoassay; LT, leukotriene; PBS, phosphate-buffered saline; OVA, ovalbumin

\begin{abstract}
Airway structural changes that occur in patients with asthma in response to persistent inflammation are termed airway remodeling. The cysteinyl leukotrienes $\left(\mathrm{LTC}_{4}, \mathrm{D}_{4}\right.$ and $\left.\mathrm{E}_{4}\right)$ are known to play important roles in the pathobiology of asthma. To evaluate the effect of low dose montelukast (MK) on the development of airway remodeling using a chronic murine model of allergic airway inflammation with subepithelial fibrosis, BALB/c mice, after intraperitoneal ovalbumin (OVA) sensitization on days 0 and 14 , received intranasal OVA periodically on days 14-75. MK treated mice received montelukast sodium intraperitoneally on days 26-75. The OVA sensitized/challenged mice developed an extensive eosinophil cell inflammatory response, goblet cell hyperplasia, mucus occlusion, and smooth muscle hypertrophy of the airways. In addition, in OVA sensitized/challenged mice, dense collagen deposition/fibrosis was seen throughout the lung interstitium surrounding the airways, blood vessels, and alveolar septae. The cysteinyl leukotriene 1 (CysLT1) receptor antagonist, MK significantly reduced the airway eosinophil infiltration, goblet cell hyperplasia, mucus occlusion, and lung fibrosis except airway smooth muscle hypertrophy in the OVA sensitized/challenged mice. The OVA sensitized/challenged mice had significantly increased
\end{abstract}

epithelial desquamation compared with control mice. MK markedly reduced epithelial desquamation of airways in OVA/MK treated animals compared with OVA sensitized/challenged mice. MK treatment did not affect the levels of CysLT in lung tissue. Our results show that the important role of cysteinyl leukotrienes in the pathogenesis of asthma. Lower dose of CysLT1 receptor antagonism has a significant anti-inflammatory effect on allergen-induced lung inflammation and fibrosis but not airway smooth muscle hypertrophy in an animal model of asthma.

Keywords: anti-asthmatic agents; asthma; leukotriene antagonists; leukotrienes; montelukast; SRS-A

\section{Introduction}

The inflammatory process that characterizes the pathophysiology of asthma involves a number of cells and mediators. Airway structural changes that occur in patients with asthma in response to persistent inflammation are termed airway remodeling and include airway wall thickening, subepithelial fibrosis, and hyperplasia of mucus glands, myofibroblasts, smooth muscle, and vasculature (Elias et al., 1999). The cysteinyl leukotrienes (CysLTs; LTC $_{4}$, $\left.D_{4}, E_{4}\right)$ are known to play an important role in the pathobiology of asthma. These compounds, derived from arachidonic acid via the 5-lipoxygenase pathway, are produced in cells of inflammation such as eosinophils, mast cells, monocytes, and basophiles (Lewis et al., 1990). The leukotrienes have multiple effects that contribute to the airways obstruction and inflammation that characterize asthma. Inhalation of $\mathrm{LTE}_{4}$ causes eosinophil influx into the airway wall (Gauvreau et al., 2001). In vitro studies with the CysLTs increased venous permeability (Joris et al., 1987), mucus secretion (Marom et al., 1982), and decreased activity of the respiratory cilia were shown (Bisgaard and Pederson, 1987). It is now widely recognized that CysLTs play an important role in asthma, participating in both the bronchoconstriction and the chronic inflammatory component of the disease.

Clinical studies of antileukotriene agents have provided direct evidence of the role of the CysLTs in 
clinical asthma. In a previous study with MK-0571, a leukotriene receptor antagonist, protection against both early-and late-phase bronchoconstriction due to inhaled allergens was demonstrated (Rasmussen et al., 1992). Montelukast (MK-0476) is a potent and specific CysLT1 receptor antagonist (Jones et al., 1995). In previous studies, it has been shown that Montelukast (MK) has a high dose (10.25 or 62.5 $\mathrm{mg} / \mathrm{kg}$ ) or dose-dependent (1-10-100 mg/kg) anti-inflammatory response on allergen induced lung inflammation in an animal model of persistent asthma (Blain and Sirois, 2000; Wu et al., 2003).

The aim of this study was to determine the effects of lower dose MK on the development of airway remodeling using a chronic murine model of allergic airway inflammation with subepithelial fibrosis. In addition, we investigated its influence on the levels of CysLTs in a murine model of asthma.

\section{Meterials and Methods}

\section{Experimental design}

The local ethics committee of Firat (Euphrates) University has approved the experimental protocol. $B A L B / c$ mice were received from Department of Virology, School of Veterinary Medicine, and Firat (Euphrates) University. Six-to 8-week-old BALB/c mice $(n=22)$ were divided into three groups. Ovalbumin (OVA) $(n=6)$ and MK treated (OVA/MK) $(n=10)$ groups were immunized by intraperitoneal (I.P.) injections of $100 \mu \mathrm{g}$ of OVA complexed with alum on days 0 and 14 (Henderson et al., 1996). Mice received an intranasal dose of $500 \mu \mathrm{g}$ OVA on days $14,27,28,29,47,61,73,74$, and 75 . The control group (PBS) $(n=6)$ received normal phosphate buffered saline (PBS) with alum i.p. on days 0 and 14 and PBS without alum intranasally on days 14, 27, 28, 29, 47, 61, 73, 74, and 75 (Henderson et al., 2002). A group of MK treated mice was administered with montelukast sodium [Merck\&Co., Inc. (Rahway, NJ)] that was dissolved in PBS. Then MK (1 $\mathrm{mg} / \mathrm{Kg}$, once a day) was injected intraperitoneally beginning on day 26 of the protocol and continuing until day 75 . In accordance with previous studies $1 \mathrm{mg} / \mathrm{Kg}$ dose was accepted as low dose (Blain and Sirois, 2000; Eum et al., 2003; Wu et al., 2003).

On day $77,48 \mathrm{~h}$ following the final intranasal or PBS treatment of mice from each experimental group, the mice were exsanguinated by cervical dislocation and the lungs were removed.

\section{Lung histology}

The lungs of the mice were obtained and fixed in $10 \%$ formalin solution. After embedding in paraffin, the tissues were cut into $5-\mu \mathrm{m}$ sections and stained with hematoxylin-and-eosin (H\&E) to assess the inflammatory cell infiltrate $(0-4+$ scale; 0 , no cell infiltration;,$+ \sim 0-25 \%$ cell infiltration;,$++ \sim 25-50 \%$ cell infiltration;,$+++ \sim 50-75 \%$ cell infiltration; +++ ,$+ \sim 75-100 \%$ cell infiltration). Luna's method was performed to identify eosinophil infiltration (as a percent of total inflammatory cells) into the airway area (0-4+ scale, as described above) (Luna, 1979). Masson's trichrome staining was performed to determine collagen deposition in the lungs $(0$ to $4+$, as described above) (Sheehan and Hrapchac,

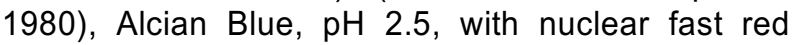
counterstaining to identify airway goblet cells (as percent of total airway cells). The degree of mucus plugging of the airways was classified on a semiquantitative scale from 0 to $4+$ as follows; 0 , no mucus;,$+ \sim 0-25 \%$ occlusion;,$++ \sim 25-50 \%$ occlusion;,$+++ \sim 50-75 \%$ occlusion;,$++++ \sim 75-100 \%$ occlusion. Airway smooth muscle thickness was evaluated in lung sections stained by $H \& E$ by measuring the thickness of the smooth muscle cell layer beneath the airway epithelial cell basement membrane at the three sites tangential to each airway cross section examined by ocular micrometer (Henderson et al., 2002). The ratio of airways that occurred epithelial desquamation to total airways was evaluated on a scale as described above. Two observers blinded to the protocol design performed the histological and morphometric analysis by light microscopy. A minimum of 10 fields throughout the upper and lower left lung tissue were randomly examined for the morphometric analysis.

\section{Quantitation of $\mathrm{LTC}_{4}, \mathrm{LTD}_{4}, \mathrm{LTE}_{4}$ in lung tissues}

Levels of CysLTs in lung tissues of three groups of mice were measured with commercially available enzyme-linked immunosorbent assay (ELISA) kits (Cysteinyl Leukotriene EIA kit, Assay Designs Inc. MI) according to the manufacturer's instruction. Briefly, one lung from each mouse was ground, using a mortar and pestle and ground glass $11 \mathrm{~g}$ lung tissue was broken with $1 \mathrm{ml}$ Assay Buffer (Tris-buffered saline)]. The solution of ground lung and ground glass was then centrifuged at $3,000 \mathrm{rpm}$ for $10 \mathrm{~min}$. The prostaglandin synthetase inhibitors $(10 \mu \mathrm{g} / \mathrm{ml})$ (meclofenamic acid, SIGMA Chemical Co) were added to supernatants. The supernatant was then frozen at $-80^{\circ} \mathrm{C}$ for later use. The supernatant was added to 2 plates for each sample on EIA LT standards $(2,500 \mathrm{pg} / \mathrm{ml}, 1,250$ $\mathrm{pg} / \mathrm{ml}, 625 \mathrm{pg} / \mathrm{ml}, 312 \mathrm{pg} / \mathrm{ml}, 156 \mathrm{pg} / \mathrm{ml}$ and 78 $\mathrm{pg} / \mathrm{ml}$ ) and superior aliquot of tissue homogenates. After incubating with chromogen, the reaction was stopped by adding stop solution and color reactions were read on $450 \mathrm{~nm}$ optic density. 


\section{Statistical analysis}

All statistical analyses were performed using SPSS v10.0 software. Results were expressed as mean \pm standard deviation (SD). Kruskall Wallis and MannWhitney $U$ test were used to compare the variables. A $P$-value of less than 0.05 was considered statistically significant.

\section{Results}

In our study, $48 \mathrm{~h}$ after the final OVA or PBS treatment in mice from each experimental group, lung tissue was obtained to assess inflammatory cell infiltration, mucus release, and collagen deposition. The effect of MK on airway inflammation and remodeling was determined.

\section{Cellular infiltration of lung interstitium}

The mean total inflammatory cell infiltration score in OVA-sensitized/challenged animals was significantly higher than that in control animals $(2.33 \pm 0.51,1.0$ $\pm 0.89, P=0.006$, respectively). In the OVA-sensitized/challenged animals, a mean eosinophil number score of $2.66 \pm 0.81$ was seen representing $25-50 \%$ eosinophil cell infiltration of the lung interstitium. It was significantly higher than that of control animals (2.66 $\pm 0.81, \quad 0.5 \pm 0.54, \quad P=0.003$, respectively) (Figures $1 \mathrm{~A}$ and $\mathrm{B}$ ). CysLT1 receptor antagonism by MK inhibited the eosinophil infiltration but not total inflammatory cells infiltration of the lung tissue in OVA-sensitized/challenged mice $(P=0.002$, OVA/ MK versus OVA for eosinophils) (Figures $1 \mathrm{C}, 2 \mathrm{~A}$ and $2 B$ ). The mean eosinophil number score in OVA/MK treated group was $0.90 \pm 0.73$.

\section{Airway goblet cell hyperplasia and mucus occlusion}

Goblet cell hyperplasia was observed in the OVAsensitized/challenged animals but not in PBS control animals (Figures 1D and 1E). In the OVA-sensitized/ challenged animals, goblet cells increased to 25.83 $\pm 15.62 \%$ of airway cells compared to $1.5 \pm 1.37 \%$

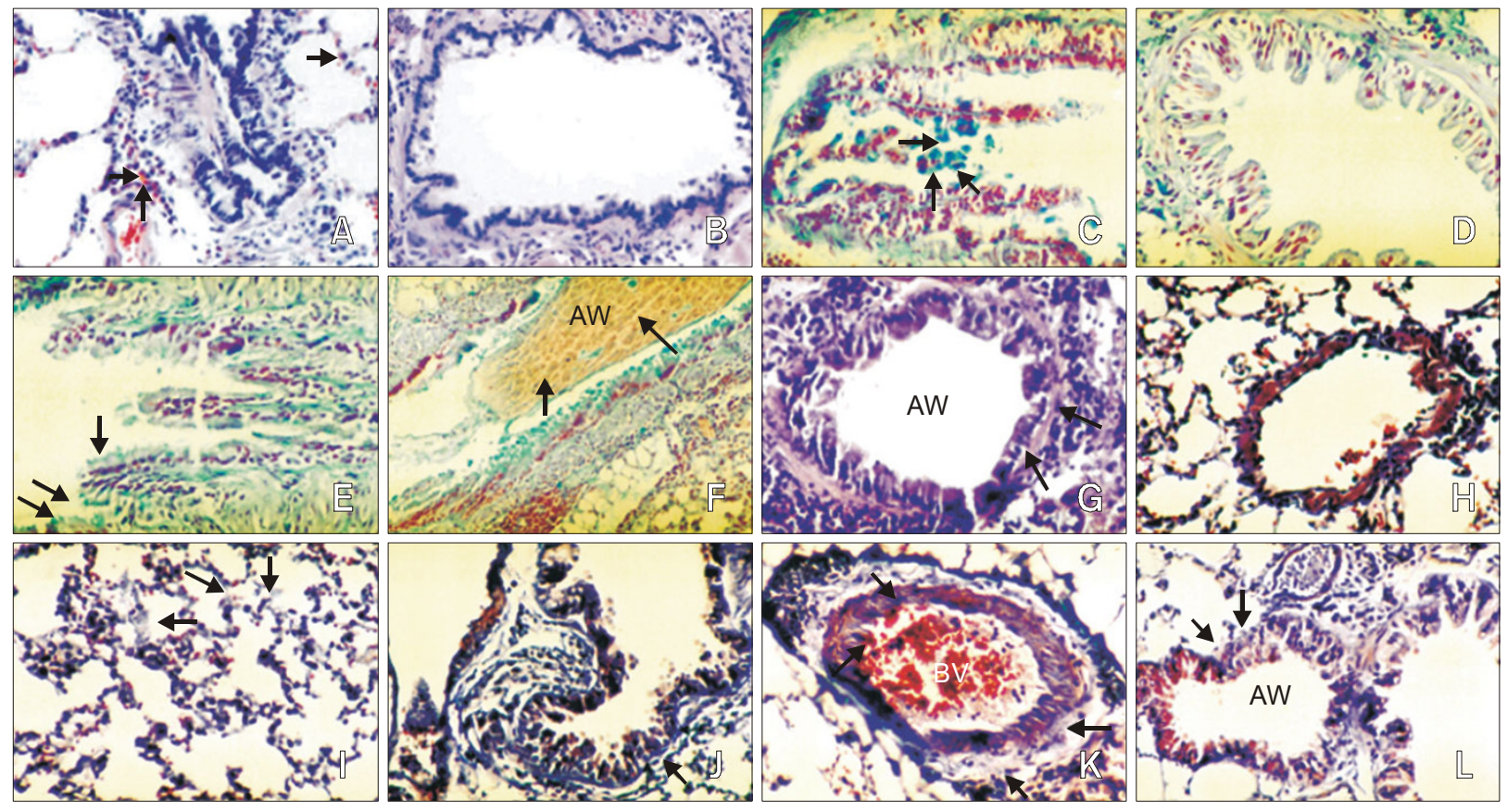

Figure 1. In the OVA sensitized/challenged mice, eosinophil infiltrate (arrows) around the airways is observed. Luna method, $100 \times(\mathrm{A})$. Montelukast treatment decreased the eosinophil infiltration (arrows) of the the lung interstitium around the airways. Luna method, $100 \times(\mathrm{B})$. Airway goblet cell hyperplasia (arrows) was observed in the OVA sensitized/challenged mice. Alcian blue, pH 2.5, $100 \times(\mathrm{C})$. There were no goblet cell hyperplasia and mucus occlusion in the PBS control mice. Alcian blue, pH 2.5, $100 \times$ (D). MK treatment decreased goblet cell hyperplasia (arrows) and mucus occlusion in the lung interstitium. Alcian blue, $\mathrm{pH} 2.5,100 \times(\mathrm{E})$. Mucus occlusion (arrows) of the airway (AW) lumen is seen in the OVA sensitized/challenged mice. Alcian blue, pH 2.5, $100 \times(\mathrm{F})$. Airway smooth muscle hypertrophy (arrows) was observed surrounding the airways in the OVA sensitized/challenged mice. Hematoxylin-and-eosin, $100 \times(\mathrm{G})$. There was no collagen deposition/fibrosis in the lung interstitium and blood vessels in PBS control mice. Masson's trichrome, $100 \times(\mathrm{H})$. Extensive collagen deposition (arrows) was seen in the lung interstitium in the OVA sensitized/challenged mice. Masson's trichrome, $100 \times(\mathrm{I})$. In the OVA sensitized/challenged mice, subepithelial fibrosis (arrows). Masson's trichrome, $100 \times(\mathrm{J})$ and blood vessel fibrosis (arrows). Masson's trichrome, $100 \times(\mathrm{K})$ were observed. MK treatment decreased collagen deposition/fibrosis (arrows) in the lung interstitium around the airways. Masson's trichrome, $100 \times(\mathrm{L})$. 
A

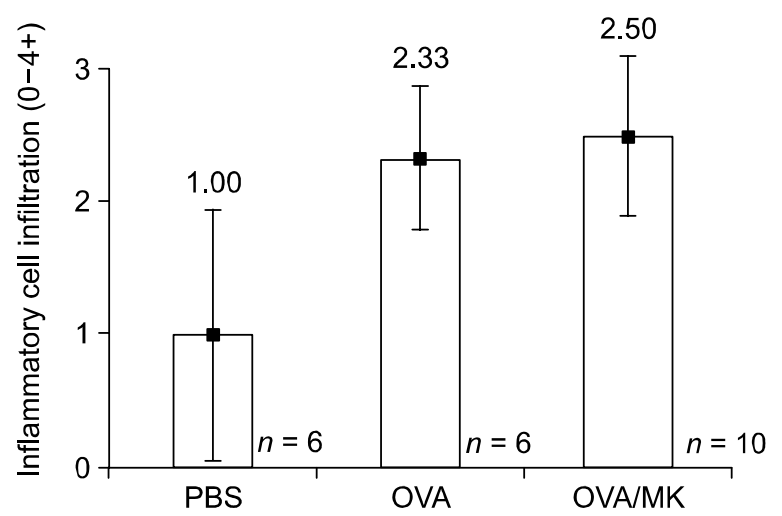

B

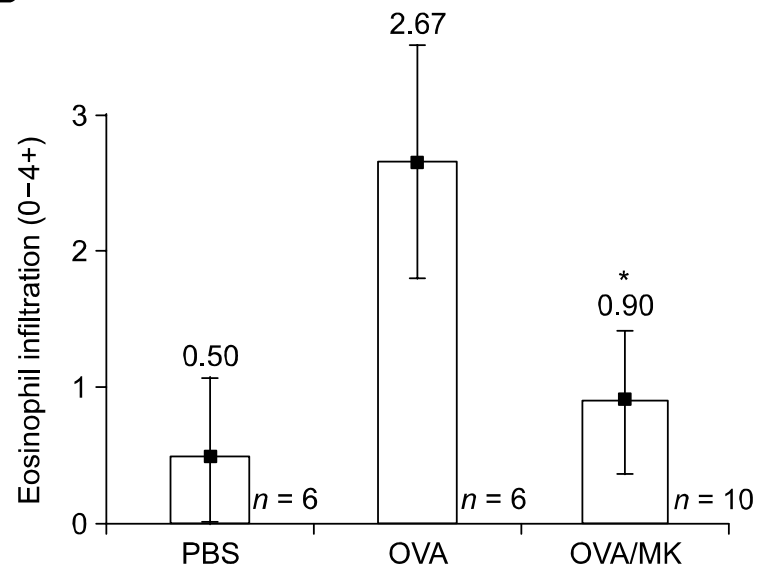

Figure 2. CysLT1 receptor blockade reduces the intensity of eosinophils in the lung interstitium after OVA challenge. The intensity of total inflammatory cells $\left(0-4+\right.$ scale) $(A)$ and eosinophils $\left(0-4+\right.$ scale) $(B)$ present in lung tissue from each group as the mean $\pm S D$. ${ }^{*} P=0.002$ versus OVA by Mann-Whitney U test.

3

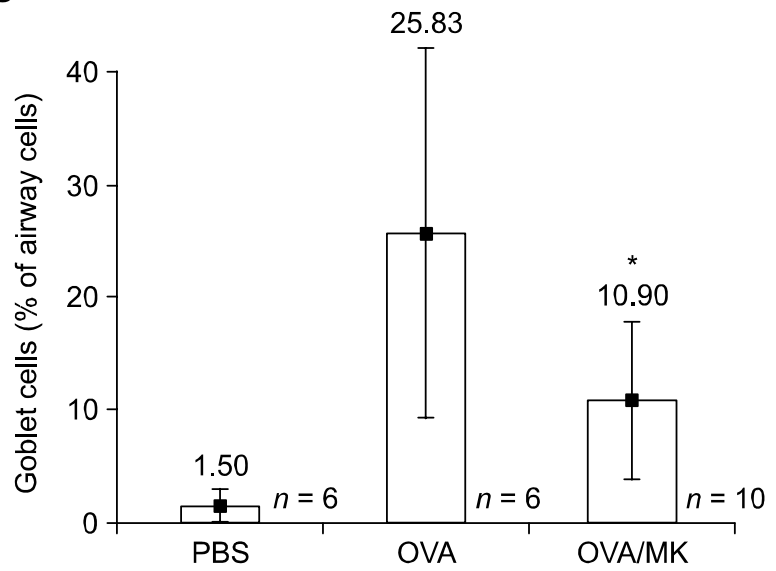

4

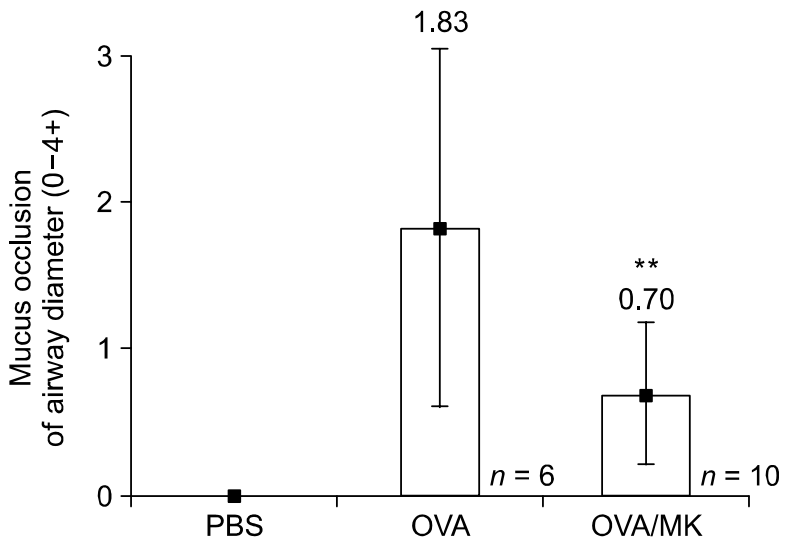

Figure 3 and 4. MK markedly reduced airway goblet cell hyperplasia and the airway mucus occlusion (respectively, ${ }^{*} P=0.018,{ }^{* *} P=0.016,0 \mathrm{VA} / \mathrm{MK}$ versus OVA-sensitized/challenged) in the OVA-sensitized/challenged animals. The percentage of goblet cells hyperplasia (3) and occlusion of airway diameter by mucus $(0-4+$ scale) $(4)$ for each group.

of airway cells in control mice $(P=0.004$, OVA versus PBS). MK markedly reduced airway goblet cell hyperplasia $(P=0.018$, OVA/MK versus OVA) (Figures $1 \mathrm{~F}$ and 3 ). In the OVA/MK animals, the percentage of goblet cell was $10.90 \pm 9.66$. There was a significant increase in airway mucus secretion in the OVA-sensitized/challenged animals compared with PBS control animals $(P=0.002)$ (Figures 1E and $1 \mathrm{G})$. The mean occlusion score was $1.83 \pm 1.16$ in OVA-sensitized/challenged animals and $0.0 \pm$ 0.00 in PBS control mice. The OVA-sensitized/ challenged animals had $0-25 \%$ occlusion of the airway lumen by mucus. MK blocked the airway mucus occlusion in the OVA-sensitized/challenged animals. In the OVA/MK animals, the mean occlusion score was $0.81 \pm 1.00$ (Figure $1 \mathrm{~F}, 4, P=0.016$, OVA/MK versus OVA-sensitized/challenged).

\section{Airway smooth muscle hypertrophy}

OVA-sensitized/challenged animals had a significantly increased airway smooth muscle thickness compared with PBS control animals $(8.33 \pm 1.25$ $\mu \mathrm{m}, 6.50 \pm 1.18 \mu \mathrm{m}, P=0.035$, respectively). MK treatment reduced the airway smooth muscle hypertrophy but not statistically significant $(8.33 \pm 1.25$ $\mu \mathrm{m}, 6.95 \pm 1.58 \mu \mathrm{m}, P=0.102$ OVA versus OVA/ $\mathrm{MK}$ ) (Figures $1 \mathrm{~B}$ and $1 \mathrm{H}$ ). In addition, there was no 
significant difference in airway smooth muscle thickness between PBS control mice and OVA/MK treatment animals $(P=0.742)$ (Figure 5$)$.

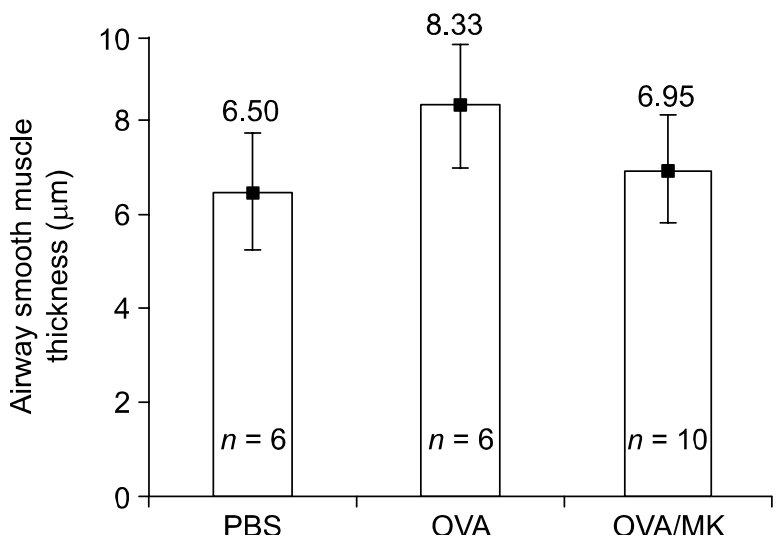

Figure 5. Airway smooth muscle thickness in the OVA-sensitized/challenged mice was reduced by MK treatment but not statsitically significant. Airway smooth muscle thickness $(\mu \mathrm{m})$ for each group.

\section{A}

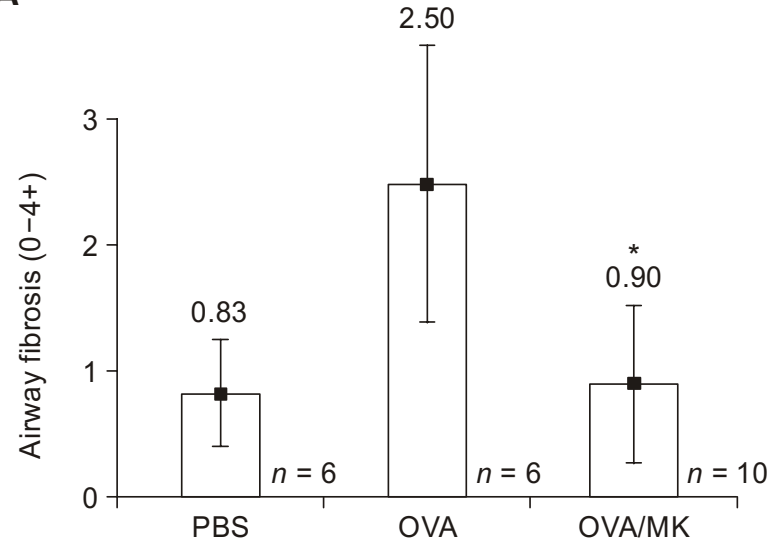

C

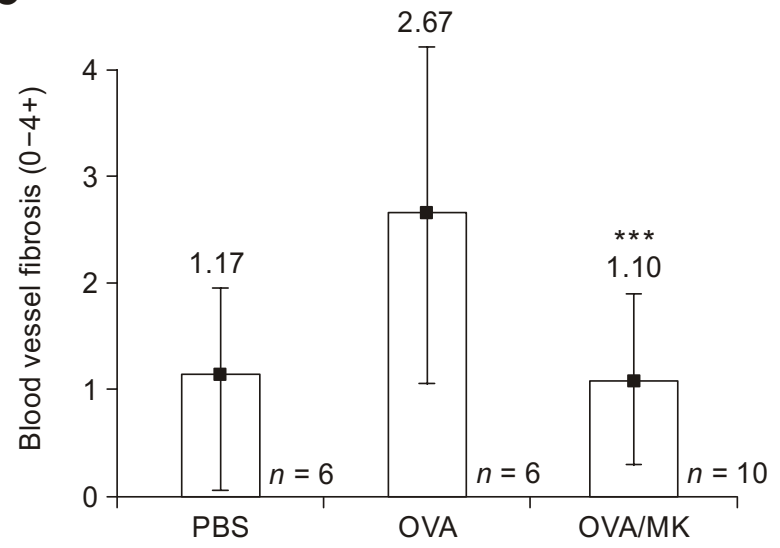

\section{Airway collagen deposition/fibrosis}

In OVA sensitized/challenged mice, dense collagen deposition/fibrosis was seen throughout the lung interstitium surrounding the airways, blood vessels, and alveolar septae (Figure 1/-L). The mean airway and alveolar septae fibrosis score was significantly higher in OVA sensitized/challenged animals than in PBS control mice $(2.50 \pm 1.04,1.66 \pm 0.81$ in OVA sensitized/challenged mice, $0.83 \pm 0.40,0.00 \pm 0.00$ in PBS control animals, $P=0.008, P=0.02$, respectively). However, there were no significant differences in blood vessels fibrosis score between OVA sensitized/challenged mice and PBS control mice $(2.66 \pm 1.50,1.16 \pm 0.75$, respectively, $P=0.06)$. MK therapy significantly reduced lung fibrosis. The mean airway, blood vessels, and alveolar septae fibrosis scores were significantly lower in OVA/MK animals compared with those of OVA sensitized/ challenged mice $(0.90 \pm 0.87,1.10 \pm 1.10,0.60 \pm 0.69$ in OVA/ MK mice, $P=0.012, P=0.039, P=0.021$ OVA versus OVA/MK, respectively) (Figure 6).

B

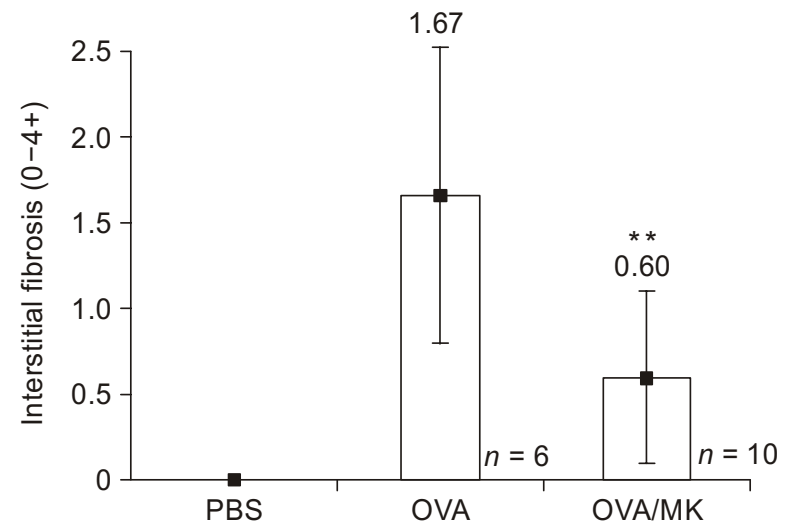

Figure 6. The intensity of airway (A), interstitial (B) and blood vessels (C) fibrosis for each group. MK therapy reduced lung fibrosis (respectively, ${ }^{*} P=$ $0.012,{ }^{* *} P=0.021,{ }^{* * *} P=0.039$ OVA/MK versus OVA-sensitized/challenged). 


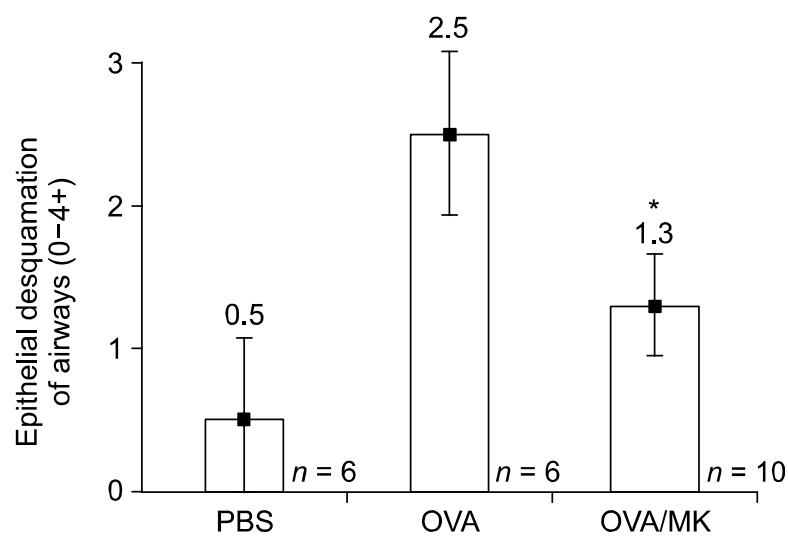

Figure 7. Effect of montelukast on OVA induced airway epithelial desquamation. ( ${ }^{*} P=0.003 \mathrm{OVA} / \mathrm{MK}$ versus OVA-sensitized/challenged). The mean epithelial desquamation score of airway in all groups.

\section{Airway epithelial desquamation}

The mean epithelial desquamation of airway score was $0.5 \pm 0.54$ in PBS control mice, $2.5 \pm 0.54$ in OVA sensitized/challenged mice, and $1.30 \pm 0.48$ in OVA/MK mice. The OVA sensitized/challenged mice had a significantly increased epithelial desquamation score compared with PBS control animals $(P=$ $0.003)$. The OVA/MK animals had a significantly lower epithelial desquamation score than OVA sensitized/challenged mice $(P=0.003)$ (Figure 7$)$.

The levels of $\mathrm{LTC}_{4} / \mathrm{D}_{4} / \mathrm{E}_{4}$ in lung tissue were elevated significantly in OVA sensitized/challenged mice $(1193.33 \pm 55.73 \mathrm{pg} / \mathrm{ml}, P=0.004)$ and in OVA/MK mice (1164.00 $\pm 72.44 \mathrm{pg} / \mathrm{ml}, P=0.001)$, compared with PBS control mice $(61.83 \pm 10.72)$. MK treatment did not affect the levels of CysLT in lung tissue. There was no significant difference in the levels of CysLT between OVA sensitized/challenged mice and OVA/MK treatment animals $(P=$ 0.293) (Figure 8).

\section{Discussion}

In the current study, it was evaluated the effects of low dose leukotriene receptor antagonist, montelukast, on the airway remodeling for chronic asthma in a mouse model. Our findings suggest that pretreatment with low dose montelukast for chronic allergic asthma markedly decreased eosinophil infiltration into the lung interstitium, goblet cell hyperplasia with airway occlusion with mucus and increased collagen deposition around the airways and blood vessels without a significant decrease airway smooth muscle thickness. However, the levels of CysLTs were not affected by MK therapy.

It is now widely accepted that chronic airway

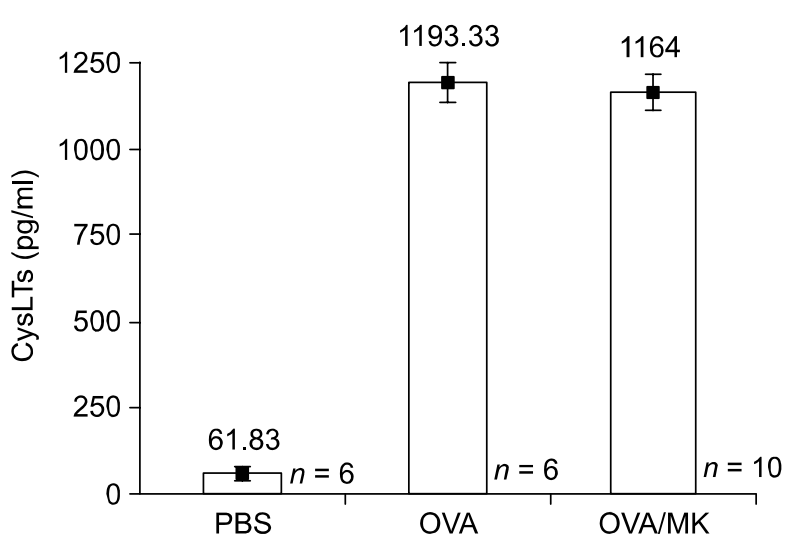

Figure 8. The CysLTs levels for each group. Montelukast did not reduce the levels of CysLTs in the OVA-sensitized/challenged mice.

inflammation plays a key role in asthma. The relationship between inflammation and structural changes is speculative. One generally accepted proposal is that remodeling is a direct result of a switch from acute to chronic inflammation followed by healing (Bousquet et al., 2000). For this reason, anti-inflammatory agents will not necessarily prevent or attenuate the process of remodeling (Jeffery, 2001). All guidelines focus on the treatment of inflammation in asthma although there are differences between them and the process of airway wall remodeling, for which there is no defined treatment yet fully validated (Bousquet et al., 2000).

Leukotrienes play important roles in asthma and are thought to have the ability to induce a variety of effects including bronchoconstriction and inflammatory cell recruitment. CysLTs have potent effect on leukocyte trafficking, airway mucus secretion, and collagen synthesis (Henderson et al., 2002). CysLTs are released by most cells involved in the airways inflammation and particularly by eosinophils (Shaw et al., 1984). Inhalation of $\mathrm{LTE}_{4}$ (Laitinen et al., 1993) or $\mathrm{LTD}_{4}$ (Diamant et al., 1997) induces the recruitment of eosinophils in the airways, possibly in part by inducing P-selectin expression on endothelial cells (Datta et al., 1995). CysLT1 receptors are expressed in human eosinophils (Figueroa et al., 2001), and their activation by CysLTs may lead to eosinophil recruitment to inflammatory sites. $\mathrm{LTB}_{4}$ is a potent chemoattractant and activator of neutrophils (Claesson et al., 1992). In our study, the increased eosinophil cell infiltrate was observed in the lung interstitium of OVA-sensitized/challenged mice. The migration of eosinophils into the airways involves several steps. Derived from myeloid progenitors in the bone marrow, mature eosinophils circulate briefly in the peripheral blood and home to the site of inflammation under the action of several factors 
including cytokines and chemokines (Wardlaw et al., 1995). The mechanisms by which CysLTs induce airway eosinophilia are unclear. It is plausible that CysLTs promote airway eosinophilia by modulating the expression of cytokines (Underwood et al., 1996). In our study, we demonstrated that low dose of MK inhibited the eosinophil infiltration of the lung tissue in OVA-sensitized/challenged mice. Recent studies have shown a reduction in airway eosinophilia in asthmatic subjects treated with CysLT1 receptor antagonists (Nakamura et al., 1998; Pizzichini et al., 1999), suggesting chemotactic effects of the CysLTs in vivo. CysLTs have been shown to attract eosinophils, and LT antagonists could potentially block these effects. Chan et al. (1990) showed administration of $\mathrm{LTD}_{4}$ induced a 2.5 -fold increase in conjunctival radioactivity (a measure of eosinophil chemotaxis) in vivo. Utilizing aerolized $\mathrm{LTD}_{4}$, Underwood et al. (1996) demonstrated inhaled LTs elevated BAL eosinophils in guinea-pig airways; increased eosinophil numbers were confirmed histologically in the bronchial epithelium and subepithelium. In current study, marked eosinophilia developed following chronic allergen challenges, and eosinophilias were attenuated by MK therapy. These results are consistent with prior observations of CysLTs antagonists in allergic airway responses of humans (Taylor et al., 1991), sheep (Abraham et al., 1993), rats (Ihaku et al., 1999) and mice (Blain and Sirois, 2000). Wu et al. (2003) demonstrated that the high dose CysLT1 receptor antagonist MK reduced eosinophil recruitment into airway by $>90 \%$ after allergen challenge in sensitized mice. This was associated with a dramatic reduction in the number of neutrophils, eosinophils and lymphocytes in the BAL, whereas in the study by lhaku et al. (1999) only a reduction in mononuclear cells was found. In our study, total inflammatory cell infiltration was not changed by MK therapy. This situation can be explained by the lower dose of MK that was used in our study. In general, it is known that high dose leokotriene receptor antagonist therapy suppressess the inflammatory cell infiltration sufficiently, especially eosinophils in a mouse model asthma. Blain and Sirois (2000) showed that MK-571 produced a dose-dependent inhibition of the infiltration of the eosinophils in the bronchoalveolar lavage and a total inhibition of neutrophil infiltration. Wu and collagues (Wu et al., 2003) showed that a high dose MK reduced the number of neutrophils, eosinophils and lymphocytes in the BAL, whereas in the study by Ihaku et al. (1999) reduction in only mononuclear cells was found by lower dose MK therapy. On the other hand, Eum et al (2003) demonstrated that the number of eosinophils and total cells were significantly reduced by both dose of $\mathrm{MK}(3 \mathrm{mg} / \mathrm{kg}$ and
$10 \mathrm{mg} / \mathrm{kg}$ ) in animal model of asthma. In this study, we tried to achieve the lower dose and long-term effect of MK on airway remodeling and the levels of CysLTs were measured. It was shown that MK reduced lung eosinophil but not total cell infiltration.

Epithelial goblet cells and mucus-secreting submucosal glands are the major sources of luminal mucus. Goblet cell hyperplasia is a feature of the airways in asthma (Jeffery, 2001). In vivo studies with the CysLTs have shown increased venous permeability (Joris et al., 1987), mucus secretion (Marom et al., 1982), and decreased activity of the respiratory cilia (Bisgaard and Pedersen, 1987). The CysLTs are also potent mucus secretagogues with greater activity in causing mucus secretion from isolated human bronchial tissue than $\mathrm{LTB}_{4}$ or cyclooxygenase products of arachidonic acid metabolism (Larieve'e et al., 1994). CysLT1 receptor, whose expression has been demonstrated on bronchial smooth muscle cells and various inflammatory cell types in the lung, is responsible for the proinflammatory actions, including increased microvascular permeability with edema formation and increased mucus secretion, possessed by CysLTs (Samuelsson, 2000). Our results showed that CysLTs are also involved in airway goblet cell hyperplasia and mucus occlusion of the airway lumen as CysLT1 receptor blockade by this dose MK significantly reduced the allergen-induced goblet cell hyperplasia and mucus occlusion in the airways observed in OVA sensitized/challenged mice. Similarly, Henderson et al. (2002) demonstrated that the numbers of goblet cells in the airways in OVA sensitized/challenged mice were significantly decreased by the same dose of CysLT1 receptor blockage. They showed that inhibition of IL-4 and IL-13 production by $\mathrm{LT}$ receptor antagonism might be an important mechanism of reducing goblet cell hyperplasia and mucus hypersecretion in allergic airways.

Smooth muscle mass is usually increased in large and/or small airways in both fatal and non-fatal cases of asthma (Carroll et al., 1993). There is a 3-to-4-fold increase in muscle volume in asthmatic airways by comparison to normal subjects (Hogg, 1993). CysLTs may alter remodeling because they increase proliferation of airway smooth muscle (Cohen et al., 1995; Panettieri et al., 1998) and airway epithelial cells (Leikauf et al., 1990) and $\mathrm{LTC}_{4}$ was shown to up-regulate collagenase expression in human lung fibroblasts (Medina et al., 1994). LTD augments epidermal growth factor-induced human airway smooth muscle proliferation in vitro (Panettieri et al., 1998). Previous studies of cysLT antagonists in allergic airway responses of Brown Norway rats (Wang et al., 1993; Salmon et al, 1999) and mice (Henderson et al., 2002) demonstrated 
that allergen-induced increases in airway smooth muscle are significantly reduced by treatment with a CysLT1 receptor antagonist. In contrast to these studies especially Henderson et al. (2002) where same dose MK was used, we did not observe significant differences in airway smooth muscle hypertrophy after MK therapy although there was a trend toward lower levels in OVA/MK treatment animals. The reason for this difference requires further investigation.

In asthma, remodeling is usually present in biopsies, as shown by collagen deposition on the reticular basement membrane (Bosquet et al., 2000). Airway thickening beneath the basement membrane occurs with deposition of collagen and other extracellular matrix proteins, including fibronectin, tenascin, and laminin (Elias et al., 1999). The thickened reticular layer is associated with deposition of immunoglobulin and/or collagen I and II and fibronectin (Roche et al., 1989). The additional reticulin is likely produced after activation of myofibroblasts leading to a so-called "fibrosis" of the airways (Brewster et al., 1990). Collagen deposition occurs in the connective tissue layer surrounding the blood vessels and alveolar interstitium. Our findings showed that airway collagen deposition/fibrosis was significantly reduced by MK therapy. These results indicate an important role of CysLTs in collagen deposition/lung fibrosis in this model of chronic asthma. Recent evidence also suggests that MK, a CysLT1 receptor antagonist, can significantly reduce airway remodeling in a mouse model of chronic asthma (Henderson et al., 2002).

The CysLTs are released from human lung due to allergic subjects in response to challenge with allergen (Dahlen et al., 1983). Hanazawa et al. (2000) showed significant increases in CysLTs in breath condensates of patients with moderate and severe asthma, compared with normal subjects. Early studies demonstrated that leukotrienes could be measured in biological fluids after an allergic or inflammatory insult (Jones et al., 2001). A variety of inflammatory cells that are intimately associated with the asthmatic condition have the necessary biochemical machinery to produce leukotrienes. These cells are of myeloid origin and are either constitutive to the lung (e.g. mast cells, macrophage) or are recruited to the lung by specific chemoattractant stimuli (e.g. eosinophils, neutrophils, basophils, lymphocytes) (Williams et al., 1984). Increased amounts of CysLTs are found in the BAL fluid of asthmatics compared with normal subjects (Wenzel et al., 1990) and allergen challenge induces the release of LTs into the airways in several animal models of asthma (Powell et al., 1995; Henderson et al., 1996). Volovitz et al. (1999) have shown that increased amounts $\mathrm{LTC}_{4}$ were found in the respiratory mucosa of children with persistent asthma and that MK can suppress these elevated levels. Possible explanation of these situation in this study; CysLTs promote eosinophil recruitment in the airways and eosinophil, in turn, releases leukotrienes. MK, which is a CysLT1 receptor antagonist, indirectly leads to a decrease in leukotriene concentration in the airways by reducing the influx of eosinophils. In our study, in this chronic mouse model of asthma, we found that levels of CysLTs were significantly increased in lung tissue after airway allergen challenge. The levels of CysLTs in the lung tissue of OVA sensitized/ challenged mice were not significantly different from those of the OVA/MK treated mice, although there was a significant decrease for eosinophil infiltration by MK therapy. These results suggest that decreased eosinophil cells may not be only one reason for affecting CysLTs levels. Most recently, it has been shown that primary airway epithelial cells contain a full set of CysLTs synthetic enzymes, and when activated, they release appreciable amounts of $\mathrm{LTC}_{4}$. Epithelial cells do not express the CysLT1 receptor (James et al., 1999). Thus, the production of CysLTs can occur in the absence of inflammation, and their actions on precursor mesenchymal cells may be important in augmenting airway remodeling in asthma (Holgate et al., 2003). In addition impairment of $\mathrm{PGE}_{2}$ synthesis from epithelial cells, as may exist in asthma, increases the extent to which epithelial cell-derived arachidonic acid is available for leukotriene synthesis by leukocytes (Holgate et al., 2003).

In conclusion, our results suggest that CysLTs are important in the pathogenesis of chronic allergic airway injury and fibrosis. Evidence from a mouse model of asthma demonstrated that CysLT1 receptor antagonist inhibits the airway remodeling process, including eosinophil infiltration, goblet cell hyperplasia, mucus hypersecretion, collagen deposition and lung fibrosis except airway smooth muscle hypertrophy, but does not affect the levels of CysLTs in the lung tissue. These results suggest that low dose of Montelukast may modulate the parameters of inflammation and fibrosis.

\section{References}

Abraham WM, Ahmed A, Cortes A, Sielczak M, Hallmon J. The effects of a cysteinyl leukotriene antagonist (ONO-1078) on antigen-induced responses in allergic sheep. Prostaglandins Leukot Essent Fatty Acids 1993;48:233-9

Bisgaard H, Pedersen M. SRS-A leukotrienes decrease the activity of human respiratory cilia. Clin Allergy 1987;17: 95-103

Blain JF, Sirois P. Involvement of LTD (4) in allergic pulmonary 
inflammation in mice: modulation by cysLT (1) antagonist MK-571. Prostaglandins Leukot Essent Fatty Acids 2000;62: $361-8$

Bousquet J, Jeffery PK, Busse WW, Johnson M, Vignola AM. Asthma. From bronchoconstriction to airways inflammation and remodeling. Am J Respir Crit Care Med 2000;161: 1720-45

Brewster CE, Howarth PH, Djukanovic R, Wilson J, Holgate ST, Roche WR. Myofibroblasts and subepithelial fibrosis in bronchial asthma. Am J Respir Cell Mol Biol 1990;3:507-11

Carroll N, Elliot J, Morton A, James A. The structure of large and small airways in nonfatal and fatal asthma. Am Rev Respir Dis 1993;147:405-10

Chan CC, McKee K, Tagari P, Chee P, Ford-Hutchinson A. Eosinophil-eicosanoid interactions: inhibition of eosinophil chemotaxis in vivo by a LTD4-receptor antagonist. Eur J Pharmacol 1990;191:273-80

Claesson HE, Odlander B, Jakobsson PJ. Leukotriene B4 in the immune system. Int J Immunopharmacol 1992;14:441-9

Cohen P, Noveral JP, Bhala A, Nunn SE, Herrick DJ, Grunstein MM. Leukotriene D4 facilitates airway smooth muscle cell proliferation via modulation of the IGF axis. Am J Physiol 1995;269:151-7

Dahlen SE, Hansson G, Hedqvist P, Bjorck T, Granstrom E, Dahlen $B$. Allergen challenge of lung tissue from asthmatics elicits bronchial contraction that correlates with the release of leukotrienes C4, D4, and E4. Proc Natl Acad Sci USA 1983;80:1712-6

Datta YH, Romano M, Jacobson BC, Golan DE, Serhan CN, Ewenstein BM. Peptido-leukotrienes are potent agonists of von Willebrand factor secretion and P-selectin surface expression in human umbilical vein endothelial cells. Circulation 1995;92:3304-11

Diamant Z, Hiltermann JT, Van Rensen EL, Callenbach PM, Veselic-Charvat M, Van der Veen H, Sont JK, Sterk PJ. The effect of inhaled leukotriene D4 and methacholine on sputum cell differentials in asthma. Am J Respir Crit Care Med 1997; 155:1247-53

Elias JA, Zhu Z, Chupp G, Homer RJ. Airway remodeling in asthma. J Clin Invest 1999;104:1001-6

Eum SY, Maghni K, Hamid Q, Campbell H, Eidelman DH, Martin JG. Involvement of the cysteinyl-leukotrienes in allergen-induced airway eosinophilia and hyperresponsiveness in the mouse. Am J Respir Cell Mol Biol 2003;28:25-32

Figueroa DJ, Breyer RM, Defoe SK, Kargman S, Daugherty BL, Waldburger K, Liu Q, Clements M, Zeng Z, O'Neill GP, Jones TR, Lynch KR, Austin CP, Evans JF. Expression of the cysteinyl leukotriene 1 receptor in normal human lung and peripheral blood leukocytes. Am J Respir Crit Care Med 2001;163:226-33

Gauvreau GM, Parameswaran KN, Watson RM, O'Byrne PM. Inhaled leukotriene $E(4)$, but not leukotriene $D(4)$, increased airway inflammatory cells in subjects with atopic asthma. Am J Respir Crit Care Med 2001;164:1495-500

Hanazawa T, Kharitonov SA, Barnes PJ. Increased nitrotyrosine in exhaled breath condensate of patients with asthma.

\section{Am J Respir Crit Care Med 2000;162:1273-6}

Henderson WR Jr, Lewis DB, Albert RK, Zhang Y, Lamm WJ, Chiang GK, Jones F, Eriksen P, Tien YT, Jonas M, Chi EY. The importance of leukotrienes in airway inflammation in a mouse model of asthma. J Exp Med 1996;184:1483-94

Henderson WR Jr, Tang L, Chu S, Tsao S, Chiang GKS, Jones $\mathrm{F}$, Jonas $\mathrm{M}, \mathrm{Pae} \mathrm{C}$, Wang $\mathrm{H}$, Chi EY. A role for cysteinyl leukotrienes in airway remodeling in a mouse asthma model. Am J Respir Crit Care Med 2002;65:108-16

Hogg JC. Pathology of asthma. J Allergy Clin Immunol 1993;92:1-5

Holgate ST, Peters-Golden M, Panettieri RA, Henderson WR Jr. Roles of cysteinyl leukotrienes in airway inflammation, smooth muscle function, and remodeling. J Allergy Clin Immunol 2003;111:18-36

Ihaku D, Cameron L, Suzuki M, Molet S, Martin J, Hamid Q. Montelukast, a leukotriene receptor antagonist, inhibits the late airway response to antigen, airway eosinophilia, and IL-5-expressing cells in Brown Norway rats. J Allergy Clin Immunol 1999;104:1147-54

James AJ, Lackie PM, Sampson AP. The expression of leukotriene pathway enzymes in human bronchial epithelial cells (abstract). Eur Respir J 1999;14:365S

Jeffery PK. Remodeling in asthma and chronic obstructive lung disease. Am J Respir Crit Care Med 2001;164:28-38

Jones TR, Labelle M, Belley M, Champion E, Charette L, Evans J, Ford-Hutchinson AW, Gauthier JY, Lord A, Masson P, et al. Pharmacology of montelukast sodium (Singulair), a potent and selective leukotriene D4 receptor antagonist. Can J Physiol Pharmacol 1995;73:191-201

Jones TR, Metters K, Evans J. Preclinical pharmacological studies with montelukast (singulair), a selective cysteinyl leukotriene receptor (CysLT1) antagonist. Clin Exp Allergy 2001;1:205-9

Joris I, Majno G, Corey EJ, Lewis RA. The mechanism of vascular leakage induced by leukotriene E4. Endothelial contraction. Am J Pathol 1987;126:19-24

Laitinen LA, Laitinen A, Haahtela T, Vilkka V, Spur BW, Lee TH. Leukotriene E4 and granulocytic infiltration into asthmatic airways. Lancet 1993;341:989-90

Larive'e P, Levine SJ, Rieves RD, Shelhamer JH. Airway inflammation and mucous hypersecretion. In Airway Secretion. Physiological Bases for the Control of Mucous Hypersecretion (Takishima T, Shimura S, eds), 1994, 469-511, Marcel Dekker, Inc., New York

Leikauf GD, Claesson HE, Doupnik CA, Hybbinette S, Grafstrom RC. Cysteinyl leukotrienes enhance growth of human airway epithelial cells. Am J Physiol 1990;259:255-61

Lewis RA, Austen KF, Soberman RJ. Leukotrienes and other products of the 5-lipoxygenase pathway. Biochemistry and relation to pathobiology in human diseases. $\mathrm{N}$ Engl $\mathrm{J}$ Med 1990;323:645-55

Luna LG. Manual of Histologic Staining Methods of the Armed Forces Institute of Pathology, 1979, McGraw-Hill, New York III

Marom Z, Shelhamer JH, Bach MK, Morton DR, Kaliner M. 
Slow-reacting substances, leukotrienes C4 and D4, increase the release of mucus from human airways in vitro. Am Rev Respir Dis 1982;126:449-51

Medina L, Perez-Ramos J, Ramirez R, Selman M, Pardo A. Leukotriene $\mathrm{C} 4$ upregulates collagenase expression and synthesis in human lung fibroblasts. Biochim Biophys Acta 1994; 1224:168-74

Nakamura Y, Hoshino M, Sim JJ, Ishii K, Hosaka K, Sakamoto $\mathrm{T}$. Effect of the leukotriene receptor antagonist pranlukast on cellular infiltration in the bronchial mucosa of patients with asthma. Thorax 1998;53:835-41

Panettieri RA, Tan EM, Ciocca V, Luttmann MA, Leonard TB, Hay DW. Effects of LTD4 on human airway smooth muscle cell proliferation, matrix expression, and contraction In vitro: differential sensitivity to cysteinyl leukotriene receptor antagonists. Am J Respir Cell Mol Biol 1998;19:453-61

Pizzichini E, Leff JA, Reiss TF, Hendeles L, Boulet LP, Wei LX, Efthimiadis AE, Zhang J, Hargreave FE. Montelukast reduces airway eosinophilic inflammation in asthma: a randomized, controlled trial. Eur Respir J 1999;14:12-18

Powell WS, Xu LJ, Martin JG. Effects of dexamethasone on leukotriene synthesis and airway responses to antigen and leukotriene D4 in rats. Am J Respir Crit Care Med 1995; 151:1143-50

Rasmussen JB, Eriksson LO, Margolskee DJ, Tagari $P$, Williams VC, Andersson KE. Leukotriene D4 receptor blockade inhibits the immediate and late bronchoconstrictor responses to inhaled antigen in patients with asthma. J Allergy Clin Immunol 1992;90:193-201

Roche WR, Beasley R, Williams JH, Holgate ST. Subepithelial fibrosis in the bronchi of asthmatics. Lancet 1989;1:520-4

Salmon M, Walsh DA, Huang TJ, Barnes PJ, Leonard TB, Hay DW, Chung KF. Involvement of cysteinyl leukotrienes in airway smooth muscle cell DNA synthesis after repeated allergen exposure in sensitized Brown Norway rats. $\mathrm{Br} \mathrm{J}$ Pharmacol 1999;127:1151-8

Samuelsson B. The discovery of the leukotrienes. Am J Respir Crit Care Med 2000;161:2-6
Shaw RJ, Cromwell O, Kay AB. Preferential generation of leukotriene C4 by human eosinophils. Clin Exp Immunol 1984;56:716-22

Sheehan DC, Hrapchac BB. Connective tissue and muscle fiber stains. In Theory and Practice of Histotechnology (Colombus, OH, ed), 1980, 180-201, Battelle Pres

Taylor IK, O'Shaughnessy KM, Fuller RW, Dollery CT. Effect of cysteinyl-leukotriene receptor antagonist ICl 204.219 on allergen induced bronchoconstruction and airway hyperreactivity in atopic subjects. Lancet 1991;337:690-4

Underwood DC, Osborn RR, Newsholme SJ, Torphy TJ, Hay DW. Persistent airway eosinophilia after leukotriene (LT) D4 administration in the guinea pig: modulation by the LTD4 receptor antagonist, pranlukast, or an interleukin-5 monoclonal antibody. Am J Respir Crit Care Med 1996;154:850-7

Volovitz B, Tabachnik E, Nussinovitch M, Shtaif B, Blau H, Gil-Ad I, Weizman A, Varsano I. Montelukast, a leukotriene receptor antagonist, reduces the concentration of leukotrienes in the respiratory tract of children with persistent asthma. J Allergy Clin Immunol 1999;104:1162-7

Wang CG, Du T, Xu LJ, Martin JG. Role of leukotriene D4 in allergen-induced increases in airway smooth muscle in the rat. Am Rev Respir Dis 1993;148:413-7

Wardlaw AJ, Moqbel R, Kay AB. Eosinophils: biology and role in disease. Adv Immunol 1995;60:151-266

Wenzel SE, Larsen GL, Johnston K, Voelkel NF, Westcott JY. Elevated levels of leukotriene C4 in bronchoalveolar lavage fluid from atopic asthmatics after endobronchial allergen challenge. Am Rev Respir Dis 1990;142:112-9

Williams JD, Czop JK, Austen KF. Release of leukotrienes by human monocytes on stimulation of their phagocytic receptor for particulate activators. J Immunol 1984;132:3034-40

Wu AY, Chik SC, Chan AW, Li Z, Tsang KW, Li W. Anti-inflammatory effects of high-dose montelukast in an animal model of acute asthma. Clin Exp Allergy 2003;33:359-66 